BNL-74700-2005-IR

\title{
Waste Container and Waste Package Performance Modeling to Support Safety Assessment of Low and Intermediate-Level Radioactive Waste Disposal
}

Terrence Sullivan

June 2004

Environmental Sciences Department Environmental Research \& Technology Division

\section{Brookhaven National Laboratory}

P.O. Box 5000

Upton, NY 11973-5000

www.bnl.gov

Managed by

Brookhaven Science Associates, LLC

for the United States Department of Energy under

Contract No. DE-AC02-98CH10886 


\section{DISCLAIMER}

This report was prepared as an account of work sponsored by an agency of the United States Government. Neither the United States Government nor any agency thereof, nor any of their employees, nor any of their contractors, subcontractors, or their employees, makes any warranty, express or implied, or assumes any legal liability or responsibility for the accuracy, completeness, or any third party's use or the results of such use of any information, apparatus, product, or process disclosed, or represents that its use would not infringe privately owned rights. Reference herein to any specific commercial product, process, or service by trade name, trademark, manufacturer, or otherwise, does not necessarily constitute or imply its endorsement, recommendation, or favoring by the United States Government or any agency thereof or its contractors or subcontractors. The views and opinions of authors expressed herein do not necessarily state or reflect those of the United States Government or any agency thereof. 
Waste Container and Waste Package Performance

Modeling to Support Safety Assessment of Low and Intermediate-Level

Radioactive Waste Disposal.

\author{
Terry Sullivan \\ Brookhaven National Laboratory \\ Upton, New York, USA
}

For the

\title{
INTERNATIONAL ATOMIC ENERGY AGENCY
}

\section{Co-ordinated Research Programme}

on

Long Term Behaviour of Low and Intermediate Level Waste Packages Under Repository Conditions 


\title{
Overview of the Waste Container and Waste Package Performance as it relates to Safety Assessment of Low and Intermediate-Level Radioactive Waste Disposal.
}

\author{
Terry Sullivan \\ Brookhaven National Laboratory \\ Upton, New York, USA
}

\subsection{Introduction}

Prior to subsurface burial of low- and intermediate-level radioactive wastes, a demonstration that disposal of the wastes can be accomplished while protecting the health and safety of the general population is required. The long-time frames over which public safety must be insured necessitates that this demonstration relies, in part, on computer simulations of events and processes that will occur in the future. This demonstration, known as a Safety Assessment, requires understanding the performance of the disposal facility, waste containers, waste forms, and contaminant transport to locations accessible to humans. The objective of the co-ordinated research programme is to examine the state-of-the-art in testing and evaluation short-lived lowand intermediate-level waste packages (container and waste form) in near surface repository conditions.

The link between data collection and long-term predictions is modeling. The objective of this study is to review state-of-the-art modeling approaches for waste package performance. This is accomplished by reviewing the fundamental concepts behind safety assessment and demonstrating how waste package models can be used to support safety assessment. Safety assessment for low- and intermediate-level wastes is a complicated process involving assumptions about the appropriate conceptual model to use and the data required to support these models. Typically due to the lack of long-term data and the uncertainties from lack of understanding and natural variability, the models used in safety assessment are simplistic. However, even though the models are simplistic, waste container and waste form performance are often central to the case for making a safety assessment. An overview of waste container and waste form performance and typical models used in a safety assessment is supplied.

As illustrative examples of the role of waste container and waste package performance, three sample test cases are provided. An example of the impacts of distributed container failure times on cumulative release and peak concentration is provided to illustrate some of the complexities in safety assessment and how modeling can be used to support the conceptual approach in safety assessment and define data requirements. Two examples of the role of the waste form in controlling release are presented to illustrate the importance of waste form performance to safety assessment. These examples highlight the difficulties in changing the conceptual model from something that is conservative and defensible (such as instant release of all the activity) to more representative conceptual models that account for known physical and chemical processes (such as diffusion), The second waste form example accounts for the experimental observation that often a thin film with low diffusion properties forms on the waste form surface. The implications of formation of such a 
layer on release are investigated and the implications of attempting to account for this phenomena in a safety assessment are addressed.

\subsection{Safety Assessment}

A number of important concepts distinguish safety assessment for radioactive waste disposal from typical engineering analyses. These concepts lead to a definition that emphasize safety assessment as a multi-disciplinary, iterative process focused on regulatory compliance rather than an analysis of a disposal system for the purpose of predicting actual outcomes. Safety assessment is defined as: the iterative process involving site-specific, prospective evaluations of the post-closure phase of the system with three primary objectives: 1) to determine whether reasonable assurance of compliance with quantitative regulatory performance objectives can be demonstrated, 2) to identify data, design, and model development needs for reaching defensible decisions about regulatory compliance, and 3) to identify waste acceptance criteria related to quantities of wastes for disposal. This paper deals primarily with the second aspect in the definition, namely, the identification of data design and model development needs for waste package components.

Critical to the definition and objectives are the phrases prospective modeling and reasonable assurance. These phrases infer that the results are not intended to be interpreted as "predictions" of actual behavior. The goal of safety assessment is to determine the conditions for which reasonable assurance of compliance with performance objectives can be provided; the goal is not to predict the actual outcome. Rather, the modeling is directed toward developing a sufficient understanding of the system behavior to support decisions about design and closure conditions. Because of the inherent uncertainties in the long-term processes and events, judgment will be a necessary part of the process of assessing the defensibility of the conceptual models It is important to understand that the uncertainty discussed with regard to safety assessment is really the uncertainty with respect to the decision (i.e., regulatory compliance), not the uncertainty associated with the numerical results of the assessment. The safety assessment results are largely a function of the data, design, and assumptions considered in the analysis. Changes to any one of these can result in changes in the conclusions resulting from the assessment. To develop reasonable assurance, it is necessary to obtain an improved understanding of those aspects of system performance that are important to the decision; it will not require a perfect representation of all processes. This need for professional judgment requires that careful attention must be paid to documenting, justifying, and defending the conceptual models, data selections, and results.

Safety assessments require an analysis of the health impacts resulting form disposal of radioactive wastes. This is a complex problem involving many scientific disciplines. To make the problem tractable, the safety assessments are usually conducted by dividing the analysis into components. The major components are: (1) infiltration and cover performance, (2) waste container performance, (3) waste form performance, (4) transport through the vadose zone, (5) groundwater transport, (6) biotic transport, (7) atmospheric transport, and (8) exposure and health effects to man. The results from one component are used to provide input to the other 
components until potential exposure to radioactivity is assessed and compared to dose or riskbased regulatory standards.

Waste container and waste form performance can be crucial components in conducting a defensible safety assessment. Due to the potential for the waste container and waste form to control release over long periods of time, modeling of waste package and waste form performance is required. The next sections of this paper provide an overview of waste container and waste package performance models and data requirements. This is followed by modeling examples of the impacts of container performance and waste form performance on release. The results of the model exercises are discussed in the context of safety assessment.

\subsection{Waste Container Performance}

The following discussion pertains to conditions in the United States of America. However, much of the material is relevant worldwide. In the USA, low-level waste containers span a wide variety of sizes, shapes, and materials of construction. Past practices have involved using glass bottles, cardboard boxes, polyethylene bags, wooden boxes, and metal drums. More recently, improved disposal operations have been used. A review of the shipping manifests for U.S. commercial waste disposal indicates that in the period of 1987 - 1989 approximately 80,000 waste containers were disposed of annually. The containers ranged in size from $0.00026 \mathrm{~m}^{3}$ to $20 \mathrm{~m}^{3}$ (Roles, 1990). Over $75 \%$ of the low-level waste containers are 55 gallon $\left(0.2 \mathrm{~m}^{3}\right)$ carbon steel drum. Other containers are used to meet specific purposes of the generators. These other containers are typically carbon steel drums $\left(0.02-0.3 \mathrm{~m}^{3}\right)$ and metal boxes $\left(0.4\right.$ to $\left.1.1 \mathrm{~m}^{3}\right)$. However, the more active wastes, Class $\mathrm{B}$ and $\mathrm{C}$ wastes, are often disposed in high integrity containers (HIC's). Materials used to construct HIC's include 316 stainless steel, Ferallium (a duplex stainless steel), and high-density polyethylene (HDPE). Concerns over long-term creep of HDPE have caused these containers to be surrounded by either a steel or concrete overpack. In addition, concrete containers are often used as overpacks in many countries (Hauser and Koester, 1989; Marque, 1994).

The container provides a barrier to prevent water from contacting the waste form. An important consideration in modeling the release rate from the waste package is the time over which the container remains completely intact and isolates the wastes from water. In general, the different sizes, shapes, and materials of the containers and the locally different environmental conditions would require a separate analysis of each container. However, this task would be overwhelming. To simplify the task, assumptions are made which permit containers to be grouped into a few different categories. This homogenization process typically divides container types into half a dozen groups or less. Major categories are carbon steel drums, carbon steel liners, stainless steel HIC's, Ferallium HIC's, and HDPE HIC's. Within each category of container, the performance of each individual container is assumed to be identical. A second approach hat is commonly used is to assume that containers of a certain type fail with a known distribution in time. For example, one could assume that all carbon steel containers fail between 20 and 70 years with a constant failure rate (e.g., 2\%/year). Other failure distributions (normal, log-normal) can be assumed provided that data are available to defend such choices. 
There are two major categories of container failure mechanisms. Catastrophic failure in which the container is assumed to instantly fail and no longer prevent a barrier to water contacting the waste form and the second is localized failure in which it is assumed that only a portion of the container fails at any time and it requires several years or longer to totally fail the entire container.

\subsubsection{Catastrophic Container Failure}

Catastrophic failure is typically modeled using either a user specified time of failure, or a failure time based on the container thickness and corrosion rate. For example, the time to failure for a metal container could be calculated from:

$$
t_{f}=\frac{d}{r}
$$

where $t_{f}$ is the time to failure (years), $d$ (meters) is the corrosion allowance thickness for the container and $\mathrm{r}$ (meters/year) is the general corrosion rate. The corrosion allowance does not have to be the container thickness, a smaller value can be used to account for mechanical failure when the uncorroded metal is too thin to support the overburden.

\subsubsection{Localized Container Failure}

Localized failures could result, for example, from stress corrosion cracking, weld failures, or pitting corrosion. The most common approach to modeling localized failure in metallic containers is to consider a complete wall penetration by pitting. With localized failure, the container still provides a barrier to water flow. However, the area penetrated by a pit does permit water to contact the waste form. Localized failure will permit releases in the aqueous solution phase at earlier times than assuming a failure time based on the general corrosion rate. In addition, if the container is to act as a barrier to gas phase release, releases can occur upon the first breach in the container. Although this is the expected failure route for most containers, lack of defensible data on localized failure rates frequently forces the analyst to assume catastrophic failure. Localized container failure models can be found in [Sullivan, 1989; Sullivan; 1993]

\subsubsection{Time Distributed Container Failure}

In any disposal site there will be thousands of different containers. It is not practical to model each of these containers individually. One approach (Sullivan, 2001) that is used to represent different container failure times is to provide a distribution of container failure times for each major category of container (carbon steel drums, carbon steel boxes, stainless steel drums, etc.) To account for this, the single failure time is generalized to a distribution of failure times. In theory, the distribution can be any function. In most cases, the distribution of failure time approximates known statistical distribution functions such as the uniform, normal, lognormal, or 
exponential distribution functions. The equations representing three commonly used failure distributions, instantaneous, uniform, or normal, are presented..

a) Instantaneous failure of all containers at time $t_{j}$ The failure distribution function, which represents the rate of change in container failures as a function of time, is:

$$
f\left(t-t_{j}\right)=\delta\left(t-t_{j}\right)
$$

where $\delta\left(t-t_{j}\right)$ is the Kronicker delta function. The only information required for this model is the time to failure.

This is the release rate for a single failure time for all containers .

b) Uniform Container Failure Rate

The containers fail at a uniform rate from the beginning time of failure, $t_{b}$, to the ending time of failures, $t_{\mathrm{e}}$. The failure distribution function is:

$$
\begin{aligned}
f\left(t-t_{j}\right) & =0 & & t<t_{b} \\
& =\frac{1}{\left(t_{e}-t_{b}\right)} & & t_{b} \leq t \leq t_{e} \\
& =0 & & t>t_{e}
\end{aligned}
$$

The information required for this model is the failure start time, $t_{b}$ and the failure finishing time, te.

c) Normal distribution failure rate.

If the container failure rate follows a normal distribution, the distribution function is:

$$
f(t)=\frac{1}{\sigma \sqrt{2 \pi}} e^{-(t-\mu)^{2} /\left(2 \sigma^{2}\right)}
$$

where $\sigma$ is the standard deviation and $\mu$ is the mean value for failure times.

\subsubsection{Waste form Release Calculations for Distributed Container Failure}

With a distribution of failure times, calculation of release from the waste form becomes more complicated than for a single failure time. To calculate release with a distribution of failures requires the combination of the fraction of containers failed at a given time and the release rate over the time since container failure. This can be represented as a sum over all containers

$$
R(t)=\sum_{j=1}^{n} r_{j}\left(t-\tau_{j}\right) f\left(\tau_{j}\right)
$$


where $R(t)$ is the total release rate from all waste packages

$r_{j}\left(t-\tau_{j}\right)$ is the release rate from waste package $j$ at time $t-\tau_{j}, t>\tau_{j}$

$\tau_{\mathrm{j}}$ is the failure time of the $\mathrm{j}^{\text {th }}$ container, and

$\mathrm{f}\left(\mathrm{t}_{\mathrm{j}}\right)$ is the fractional rate of containers that fail at time $t_{j}$ (in statistics this is known as the

probability density function)

The above approach is appropriate when modeling only a few containers with known failure times. However, when attempting to model a large number of containers it becomes more computationally efficient to represent the failure times with a continuous distribution that represents the range of possible failure times. With a continuous distribution of failure times, the release rate equation can be generalized as a convolution integral:

$$
R(t)=\int_{0}^{t} r(\tau) \cdot f(t-\tau) \partial \tau
$$

In this equation, we have assumed that all containers represented by the distribution of failure times have identical release rates. That is, one set of release rate parameters describes all of the containers in this computational volume. This assumption is required due to the impracticality of defining a unique set of release parameters that varies as a function of failure time. The release rate equation also assumes that the failure rate and release rates are independent processes. This is true for a single radionuclide, but is not necessarily true for species in a decay chain. In that case, the release rate depends on the time for ingrowth and decay. Approximate methods are used to calculate release in this situation.

\subsection{Corrosion Data}

Extensive data has been collected by the National Bureau of Standards (currently the National Institute of Standards and Technology) on the corrosion of carbon steels (Romanoff, 1957) and stainless steels (Gerhold, et. al., 1981) in soil environments. Testing was conducted on bare samples (i.e., unpainted metal which contrasts with LLW drums) and lasted for 17 years in over 100 soils. These data are often used as a basis for estimating container lifetime.

A review of the Romanoff data indicates that 55 gallon carbon steel drums with a nominal thickness of $1.2710^{-3} \mathrm{~m}$ (50 mils) should last between 10 and 140 years, depending on the soil environment (Sullivan and Suen, 1989). However, carbon steel is also susceptible to pitting corrosion. Models of pitting corrosion indicate that the time of first breach should be on the order of a few years for a wall thickness typical of a 55 gallon drum. For this reason, carbon steel drums are often modeled as providing no protection to the waste form (i.e., failure at closure of the facility).

Carbon steel liners are rectangular boxes which are used in shipping and are generally thicker than the carbon steel drums. The liners often carry activated metals and other higher activity wastes. Due to their thickness, typically $3.210^{-3} \mathrm{~m}$ or thicker, these containers are often given credit for protecting wastes from water contact for periods of 25 - 50 years. The database on 
pitting of carbon steels would suggest that these containers may have complete wall penetration by pitting at times of less than 25 years.

In order for a container to be approved for use as a high integrity container, the vendor must demonstrate to the Nuclear Regulatory Commission that the container will maintain a positive water seal for at least 300 years. Numerous studies have shown that, for container lifetimes in excess of two hundred years and less than a few thousand years, the peak dose to man is essentially independent of container lifetime (Kozak, et. al., 1993). For this reason, and because of the difficulties in justifying longer term extrapolations based on a limited data base, HIC's are often modeled as having a 300 year lifetime. If more credit is desired for metallic container performance, the data of Gerhold could be used for estimating the general corrosion rate for stainless steels. For Ferallium, there is very little data on its corrosion properties in soil systems. However, it was developed to be used in chemical environments that are extremely corrosive. In general, its corrosion performance is superior to stainless steels. Therefore, the data of Gerhold could be used to estimate its lifetime.

The mechanisms for degradation of HDPE performance have been reviewed (Cowgill, 1992). Mechanisms for HDPE degradation include corrosion, autocatalytic oxidation, low creep rupture, environmental stress cracking, irradiation-induced embrittlement, biodegradation, and water uptake. For typical disposal conditions, autocatalytic oxidation with biodegradation, radiation damage, and creep-rupture appear to be the most likely mechanisms for causing failure (Cowgill, 1992). However, the data is incomplete and most of the failure mechanisms can not be completely ruled out. Although the data indicates that the lifetime of HDPE containers should be well in excess of 300 years, the data base is sparse and this creates large uncertainties in the projected lifetime (Cowgill, 1992).

High Integrity Container's are designed to have a passive gas vent to prevent pressurization of the containers. Therefore, they do not provide any barrier to release of gaseous species.

In most safety assessments, container performance is evaluated through assuming that catastrophic failure of the container occurs at a time based on the physical (thickness) and material properties of the container. The limited data available for predicting container failure based on localized failure mechanisms leads to these processes being ignored in most performance assessment calculations. Consideration should be given to the effect on the sourceterm from container failure due to local processes occurring at earlier times than for catastrophic failure.

The importance of container life time on the projected release from the facility depends strongly upon the stylized assumptions used to represent the ability of engineered barriers to reduce water flow through the facility. If the engineered barriers are modeled as permitting relatively small amounts of water flow for time periods much greater than the container life time, the container life time and early releases resulting from localized failure generally do not have a large impact on projected release. Even if this is the case, this must be demonstrated for the site-specific 
conditions of the assessment. If the engineered barrier fails at times less than the container lifetime, the importance of containers in controlling release increases.

The data requirements for evaluating container performance depends upon the conceptual model used to develop the analytical model for the container. If the conceptual model assumes that all containers fail upon emplacement, no data is required. If a container is assumed to last for some period of time, data on the material (carbon steel, stainless steel, polyethylene, etc.), container thickness, container corrosion rate, and perhaps even the distribution of container failures in time may be needed.

\subsection{Waste Form Performance}

A waste stream refers to similar wastes generated from a common process. A waste stream may be placed untreated into the container, or it may be treated with sorbents or solidification agents, compacted or incinerated to reduce volume, de-watered, or surrounded with sand to minimize void space in the container. A waste form is defined as the final physical form of the contaminated material as placed in the waste container. It can be identical to the output of a waste stream (untreated wastes).

Low-level waste is a heterogeneous mix of wastes. The conceptual models for release from the waste package will depend on the physical and chemical form of these wastes. Furthermore, within each category there may be wastes with several different physical and chemical forms (e.g., for solidified wastes, solidification agents include several different types of cement, bitumen, and vinyl-ester styrene).

Evaluating the release from different waste forms on an individual basis would be impractical. Therefore, as with containers, assumptions are made to group waste forms into a few different categories. The grouping of wastes assumes that all of the different waste forms within a group have the same release mechanism, although the release rates could be different. For example, often all solidified waste forms are treated as having diffusion controlled release. However, the diffusion coefficient could vary for different solidified waste forms as well as for different radionuclides within a single waste form.

The first step in defining categories for waste forms requires determination of which waste forms contain most of the activity. Examination of the inventory data found on the commercial waste shipping manifests indicate the following major waste form types: activated metals, cement solidified wastes, dry solids (lab trash, papers, plastics, glassware, etc.), de-watered resins, evaporator bottoms, filter sludges, and solid non-combustibles (Roles, 1990; Cowgill, 1993). These seven waste-form categories contain over almost all of the total activity in wastes generated in the USA..

Even with an understanding of the major waste-form types, evaluation of the release from the waste form must be provided on a radionuclide specific basis. The distribution of a particular radionuclide in the waste forms often differs significantly from the average distribution. For 
example, in 1989 at the commercial site at Richland, Washington, $1.5 \%$ of the total activity was disposed in sorbents. However, 100\% of the Th-232 was disposed of in sorbents (Sullivan and Cowgill, 1991). When evaluating the release for any radionuclide, a detailed characterization of its inventory based on its distribution in the various waste forms is needed for more accurate modeling of the source term.

\subsection{Waste-Form Performance: Aqueous Phase}

In modeling waste-form performance, the first step involves obtaining the distribution of activity on the different waste forms and the distribution of waste forms in different containers. The container information is needed to obtain the time at which water contacts the wastes and releases begin. The distribution of inventory is needed to form a conceptual model of the processes that will control release.

The aqueous release of radionuclides from the waste form is frequently conceptually modeled as occurring through one of the following four physico-chemical processes:

- Surface rinse with partitioning,

- Diffusion,

- Dissolution, or

- Solubility limited release.

The following sections discuss models frequently used in safety assessment to represent the above processes. The list of models is not intended to be complete but rather to show the types of models used.

\subsubsection{Surface Rinse with Partitioning}

The surface rinse with partitioning model assumes that the entire inventory is released instantly upon contact with water, subject to equilibrium partitioning between the waste form and the contacting solution. The partition coefficient, which is the ratio of the contaminant mass on the waste form per unit mass of the waste form to the concentration in solution at equilibrium, is used to define the distribution of the contaminant in the system. In the extreme, zero partition coefficient, this model approximates instantaneous release of the entire waste form inventory upon contact with water. This assumption is frequently used to provide an upper bound on release or in situations where there is very little data to support use of other mechanisms to represent waste form release. Appropriate leaching data are often unavailable.

The equation to estimate the total mass released for instantaneous release(i.e., zero partition coefficient) is:

$$
M_{r}=\int_{0}^{t} \delta\left(t-t_{f}\right) M_{o} e^{(-\lambda t)}
$$


In this equation, $\mathrm{M}_{\mathrm{r}}$ is the total mass released $(\mathrm{kg}), \delta\left(\mathrm{t}-\mathrm{t}_{\mathrm{f}}\right)$ is the Dirac delta function which is a mathematical construct used to represent total instantaneous release at the time $t_{f}, t_{f}$ is the time (s) at which the waste is first exposed to the aqueous solution, $\mathrm{M}_{\mathrm{o}}$ is the initial mass $(\mathrm{kg})$ in the waste form, and is the radioactive decay constant $\left(\mathrm{s}^{-1}\right)$. In the preceding equation, if time is less than the total failure time, $\mathrm{t}_{\mathrm{f}}$, the mass release is zero. If time is greater than the total failure time, the total mass release is the inventory corrected for decay.

In the preceding equation, mass loss due to radioactive decay prior to release is modeled. However, ingrowth due to decay of other radioactive species is not. If, the radionuclide is part of a decay chain, the available mass should be modified to account for this using Bateman's equations.

When partitioning is modeled, the situation becomes much more complex. Partitioning models are characterized by a relatively large release at the time of failure followed by a slower release until the inventory is depleted. The initial release occurs to fill the initially uncontaminated solution in contact with the waste form with the equilibrium level of contamination. The slow release that follows is controlled by the rate at which the contaminant is transported away from the waste form and the equilibrium partitioning relationship. The equilibrium relationship defines the equilibrium concentration in solution. Therefore, the amount of mass released depends on the volume of the contacting solution. Thus the conceptual model for this approach needs to consider an approach to estimate the volume of the solution contacting the waste and the volume of the waste forms. The equation used to estimate the mass released when equilibrium partitioning occurs is (Sullivan and Suen, 1991):

$$
M_{r}=\frac{\left[M_{a}(t)-\left(\frac{K_{p}}{\gamma}\right) M_{s}(t)\right]}{1+\frac{K_{p}}{\gamma}}
$$

where $M_{a}(t)(\mathrm{kg})$ is the mass available for release on the waste form, $K_{p}\left(\mathrm{~kg} / \mathrm{m}^{3}\right)$ is the equilibrium partitioning coefficient, $\mathrm{M}_{\mathrm{s}}(\mathrm{t})$ is the mass in the contacting solution at time $\mathrm{t}$, and $\left(\mathrm{m}^{3} / \mathrm{kg}\right)$ is the ratio of the volume of water contacting the waste form to the mass of the waste form. When using a numerical solution technique (i.e., finite-difference or finite element), the volume of the contacting solution is selected to be the volume of the computational cell multiplied by the moisture content in that cell. The mass available for release is the mass remaining on the waste form after correcting for radioactive decay, ingrowth, and release at earlier times. From the equation, it can be shown that as the partitioning coefficient approaches zero, all of the mass is released instantaneously and the rinse release model is recovered. Also, there is a point at which there is zero release (i.e., the system is at equilibrium) and a range where release is negative (i.e., the waste form adsorbs contamination from solution). Waste form release rates are estimated by determining the mass released from the above equation and dividing by the computational time step.

\subsubsection{Diffusion Controlled Release}


The diffusion model assumes that radioactive contaminants are initially uniformly distributed throughout the waste form and the process controlling their release is diffusion through the waste form. At the boundary of the wastes, it is generally assumed that the concentration at the edge of the waste form is zero. This corresponds to the case when transport away from the waste form is much faster than within the waste form. This gives the highest diffusion gradient and therefore,

$$
\begin{gathered}
\frac{\partial C}{\partial t}=D \nabla^{2} C-\lambda C \\
C(x, y, z, 0)=C_{0} \\
C\left(x_{b}, y_{b}, z_{b}, t\right)=0
\end{gathered}
$$

highest release rates. In this case, the governing equation, initial and boundary conditions are: where $\mathrm{C}$ is the concentration in the waste form $\left(\mathrm{kg} / \mathrm{m}^{3}\right), \mathrm{D}$ is the diffusion coefficient in the waste form $\left(\mathrm{m}^{2} / \mathrm{s}\right), \lambda$ is the decay constant $\left(\mathrm{s}^{-1}\right), \mathrm{C}_{0}$ is the initial concentration, and the subscript $\mathrm{b}$ refers to points on the boundary. The preceding equation is solved and the flux, $\mathrm{J}$, (release rate

$$
J=-D \nabla C
$$

per unit area per unit time) at the surface is obtained.

The flux is integrated over the surface area of the waste form to obtain the mass release rate per unit time.

A number of analytical solutions for diffusion release from a variety of different geometries have been developed, including solutions for: semi-infinite media, as well as, finite sized cylindrical or rectangular waste forms exist (ANS 1986, Pescatore, 1991). The semi-infinite media model assumes that the waste form is characterized as being a half-plane located in the domain $\mathrm{x}<0$. The analytical solution for the flux in the presence of radioactive decay is:

$$
J=C_{0}\left[\frac{D}{\pi t}\right]^{0.5} e^{-\lambda t}
$$

where $t$ is the time since the onset of diffusion release. Notice, that the flux becomes infinite as $t$ approaches 0 . This is a result of the discontinuity in the concentration at the boundary of the waste form $(\mathrm{C}=0)$ and the initial concentration immediately adjacent to the boundary $\left(\mathrm{C}=\mathrm{C}_{0}\right)$. This behavior is found in all diffusion models. However, to handle this problem, the above expression is integrated over time and evaluated at two times ( $t$ and $t+\Delta t$ ). The integral of the flux is not infinite as $t$ approaches zero, rather it is zero. The waste form release rate can be estimated by the difference in the amount released at two times. 
The semi-infinite media approximation has been shown to be an accurate representation of the release from the waste form provided less than $20 \%$ of the original mass would have been released in the absence of decay (ANS, 1986). After this occurs, depletion of the inventory in the waste form causes the semi-infinite media model to overpredict release rates.

More mathematically accurate representations of diffusion controlled release from waste forms can be obtained by considering the finite size of the waste forms. Analytical solutions in this case are characterized by infinite series (Pescatore, 1991). These series converge slowly at small values of time and special techniques are used to enhance the convergence rate of the series.

Diffusion models provide a time-dependent release rate independent of processes occurring outside of the waste form. Other models which incorporate solution feedback effects are available (Sullivan and Suen, 1991). However, in practice, the concentration in the waste form is generally much greater than in the contacting solution and therefore, this effect is minimal. Solution feedback effects become important when solubility limits are approached. In this case, the solubility limited release model is more appropriate.

The diffusion model is most often used for wastes solidified in a binder, e.g., cement, VES, etc. The diffusion coefficient should be determined experimentally on a radionuclide specific basis for the waste stream/binder combination used for disposal. If relevant experimental data does not exist, the diffusion coefficient is often assumed to be the maximum value approved for an acceptable solidification agent by the NRC (NRC, 1991). This value is $\mathrm{D}=10^{-10} \mathrm{~m}^{2} / \mathrm{s}$.

\subsubsection{Dissolution (Constant) Release}

The dissolution model assumes congruent release of all species within the waste form at a rate controlled by the dissolution velocity of the waste form. This model is commonly applied to release from activated metals and glass waste forms. In practice, the dissolution velocity is assumed constant with a value based on experimental data for metallic corrosion or glass dissolution, as appropriate. With a constant dissolution velocity and the geometry of the waste form, the inventory fractional release rate can be calculated. The appropriate equation for estimating the mass released based on a congruent dissolution model is:

$$
M_{r}=\int u M_{a}(t) \frac{S A}{V} d t
$$

where $M_{r}$ is the mass release $(\mathrm{kg}), \mathrm{u}$ is the dissolution velocity $(\mathrm{m} / \mathrm{s}), \mathrm{M}_{\mathrm{a}}(\mathrm{t})$ is the mass available $(\mathrm{kg})$ for congruent dissolution at time $\mathrm{t}(\mathrm{s}), \mathrm{SA}$ is the surface area $\left(\mathrm{m}^{2}\right)$ and $\mathrm{V}$ is the volume $\left(\mathrm{m}^{3}\right)$ of the waste form. The waste form release rate, $R_{w}$, is the time-derivative of the above expression which is: 


$$
R_{w}=u\left(\frac{S A}{V}\right) M_{a}(t)
$$

Many performance assessment models simulate waste form release using a constant fractional release rate. From the above equation, the first three terms, u, SA, and V, can be combined to define the fractional release rate. This model can be generalized to permit a radionuclide specific release rate by defining a unique dissolution velocity (or fractional release rate) for each radionuclide.

\subsubsection{Solubility-limited Release}

The solubility limited release model permits an instantaneous release to solution until the solubility limit is reached. Further releases are controlled by the migration of radionuclides away from the waste form. A balance is achieved between the release rate and migration rate away from the waste form such that the solution concentration at the edge of the waste form remains at the solubility limit. In this case, there is a strong coupling between transport away from the waste form and waste form release rates. The solubility limited release model can be applied on a nuclide specific basis to all waste forms. It frequently becomes the rate controlling release mechanism for contaminants that have low-solubility limits in ground water, e.g., uranium and other actinides.

The solubility limited release model is often applied in conjunction with other release mechanism models. In such cases, the alternative mechanisms are assumed to control release unless the solubility limit is exceeded. If this occurs, precipitation is assumed to occur such that the solution concentration equals the solubility limit. The precipitated mass will dissolve when transport mechanisms remove the contaminant away from the waste form.

Use of the solubility limited release model for elements that have several radioactive species can be difficult. Care must be taken to insure that the solubility limit is applied simultaneously for all radionuclides for the element. This requires a multi-nuclide analysis of the source term. For example, consider two radioactive contaminants which are isotopes of the same element. To properly evaluate solubility limited release would require simultaneous estimation of the release of both isotopes, summing the concentrations of both isotopes in solution and comparing this with the elemental solubility limit. If the solubility limit was exceeded, the release calculation would have to be refined to prevent this. The different waste form liquid phase release models are provided in Table 1. 
Table $1 \quad$ Waste Form Liquid Phase Release Models

\begin{tabular}{|c|c|c|}
\hline Release Mechanism & Applicability & Comments \\
\hline Instantaneous (rinse) & $\begin{array}{l}\text { Surface contaminated wastes, } \\
\text { waste forms without release } \\
\text { rate data }\end{array}$ & Highest release rate. \\
\hline $\begin{array}{l}\text { Surface Rinse with } \\
\text { Partitioning }\end{array}$ & $\begin{array}{l}\text { Surface contaminated wastes } \\
\text { that sorb radionuclides (e.g. } \\
\text { soils, sludges, ion-exchange } \\
\text { resins). }\end{array}$ & $\begin{array}{l}\text { Release rate controlled by } \\
\text { transport of contaminants } \\
\text { away from the waste form. }\end{array}$ \\
\hline Diffusion & $\begin{array}{l}\text { Solidified Wastes (e.g. } \\
\text { cements, polyethylene, } \\
\text { bitumen). }\end{array}$ & $\begin{array}{l}\text { Release rate decreases in } \\
\text { time. Bitumen may swell due } \\
\text { to uptake of water. Diffusion } \\
\text { model is inappropriate when } \\
\text { this occurs. }\end{array}$ \\
\hline Dissolution (Uniform) & $\begin{array}{l}\text { Release controlled by surface } \\
\text { dissolution (e.g. waste } \\
\text { glasses, activated metals). }\end{array}$ & $\begin{array}{l}\text { Constant release rate } \\
\text { corrected for radioactive } \\
\text { decay }\end{array}$ \\
\hline Solubility Limited & $\begin{array}{l}\text { Radionuclides with low- } \\
\text { solubility in the expected } \\
\text { chemical environment. }\end{array}$ & $\begin{array}{l}\text { Release rate controlled by } \\
\text { transport of the species away } \\
\text { from the waste form. }\end{array}$ \\
\hline
\end{tabular}

\subsection{Waste Form Performance: Gas Phase}

Under proper environmental conditions, ${ }^{3} \mathrm{H},{ }^{14} \mathrm{C},{ }^{85} \mathrm{Kr},{ }^{129} \mathrm{I}$, and ${ }^{222} \mathrm{Rn}$ can all exist in the gas phase. Gas may be produced in a low-level waste disposal facility due to production of: a) hydrogen from anaerobic corrosion of metals; b) methane and carbon dioxide from microbial degradation of organic materials; c) failure of sealed sources of ${ }^{85} \mathrm{Kr}$; d) radiolysis to produce gaseous ${ }^{3} \mathrm{H}$ and ${ }^{129} \mathrm{I}$; e) radioactive decay of ${ }^{226} \mathrm{Ra}$ to ${ }^{222} \mathrm{Rn}$. and $\mathrm{f}$ ) volatilization of liquid ${ }^{3} \mathrm{H}$. The formation of radioactive gases may lead to release to the environment through gas-phase diffusion and advective transport mechanisms.

Estimating the gas phase release from the waste form requires evaluation of each of the above processes. Release of ${ }^{14} \mathrm{C}$ in carbon dioxide or methane $\left({ }^{3} \mathrm{H}\right.$ could also be released in methane) due to biodegradation requires a detailed analysis of the amount and types of organic material present in the facility and the rate of production of these gases. A detailed analysis of this process has found that a small fraction of the ${ }^{14} \mathrm{C}$ inventory $(5-10 \%)$ could be released in the 
gas phase under expected conditions with current inventories of biodegradable material (Yim, 1994). Smaller total amounts of tritiated gas are expected to be released. When modeling release of sealed sources is important, this is typically achieved through assuming a time-tofailure of the seal followed by total release of the inventory at that time. Radiolysis has been found to produce limited amounts of gas and can be neglected as a mechanism for gas release even at the maximum cumulative radiation dose expected in low-level waste forms, which are doses of less than $10^{6}$ Gy (Yim, 1994). At levels above $10^{6} \mathrm{~Gy}$, gas generation may become significant and estimates of its importance would depend on the dose rate as well as total dose. Release of ${ }^{222} \mathrm{Rn}$ can be calculated from the decay rate of the parent and knowledge of the distribution of the parent in the waste form. For surface contaminated wastes, release would occur upon decay. For solidified wastes, the gaseous ${ }^{222} \mathrm{Rn}$ would have to diffuse through the waste form. Diffusion of gases through solidified waste forms is likely to be much more rapid than diffusion of liquids. The different gaseous release mechanisms are displayed in Table 2

Table 2 Waste Form Gas Phase Release Models

\begin{tabular}{|l|l|l|}
\hline \multicolumn{1}{|c|}{ Release Mechanism } & \multicolumn{1}{c|}{ Applicability } & \multicolumn{1}{c|}{ Comments } \\
\hline $\begin{array}{l}\text { Anaerobic corrosion of } \\
\text { metals }\end{array}$ & Tritium containing wastes & Corrosion release $\mathrm{H}_{2}$ gas \\
\hline Microbial Degradation & $\begin{array}{l}\text { Organic Wastes containing } \\
{ }^{14} \mathrm{C} \text { or tritium }\end{array}$ & Can produce ${ }^{14} \mathrm{CO}_{2}$ or ${ }^{14} \mathrm{CH}_{4}$ \\
\hline Radiolysis & High activity wastes & $\begin{array}{l}\text { Not expected to produce } \\
\text { substantial quantities of gases } \\
\text { in LLW. }\end{array}$ \\
\hline Time to failure & Sealed sources, Kr-85. & $\begin{array}{l}\text { Majority of tritium will } \\
\text { remain in the liquid phase }\end{array}$ \\
\hline $\begin{array}{l}\text { Rolatilization, equilibrium } \\
\text { partitioning between liquid } \\
\text { and gas. }\end{array}$ & tritium wastes & Produces radon-222 gas \\
\hline
\end{tabular}

\subsection{Ingrowth of Radionuclides}

The decay of many radioactive species leads to production of other radioactive species. These progeny species will have different physical and chemical characteristics and therefore, different release and transport characteristics. The production of these progeny species needs to be addressed. In particular, decay of Th to its progeny is often important as the decay products tend 
to be more soluble and mobile than the parent. This is particularly true in the decay chain that includes ${ }^{230} \mathrm{Th}$ and produces ${ }^{222} \mathrm{Rn}$ gas. Another issue for decay chains is the long-time period required to reach secular equilibrium. For example, the activity of ${ }^{222} \mathrm{Rn}$ will continue to increase for millions of years due to decay of ${ }^{238} \mathrm{U}$. A final issue for decay chains is that several models account for ingrowth of progeny during transport outside the waste form, but very few account for ingrowth in the waste form. Recently models have been developed to address ingrowth prior to release (Sullivan, 1996, Sullivan, 2000).

In the disposal facility, flow will proceed through the cover and engineered barrier, around the wastes and out of the facility. There are many different materials and obstructions to flow. These heterogeneities, along with the potential for localized effects such as cracking of the engineered barrier, may lead to non-uniform flow through the facility. In performance assessment, the source region is typically treated as containing a steady and spatially uniform flow field.

\subsection{Example of the Role of Waste Container Performance on Safety Assessment}

To demonstrate how modeling can be sued to defend decisions on data collection needs and conceptual approach to making a safety assessment an example of the effects of distributed container failure is presented. The example was calculated with the DUST-MS computer code (Sullivan, 2001) and considered diffusion controlled release from a cylindrical waste form. In this problem, the first species, Species A, has a 44.7 year half-life, while the second species, Species B, has a $7.710^{4}$ year half-life. Three container failure modes are modeled, instant failure of all containers at 100 years after emplacement, Gaussian distribution failure rate with a mean life of 100 years and a standard deviation of 25 years, and uniform failure rate starting at 50 years and ending 150 years after emplacement. The disposal facility was started in 1950, however, this group of containers was not buried until 1965. Thus, the instant failure time is at 115 years from the problem start time, 1950. The waste form originally contains $1 \mathrm{gm}$ of Species A and species B is absent. Species B is produced from the radioactive decay of Species A. The waste form has a radius of $25 \mathrm{~cm}$ and both species have a diffusion coefficient of $10^{-8}$ $\mathrm{cm}^{2} / \mathrm{s}$. These values cause release to occur over hundreds of years (much longer than the range in container failure times).

Figure 1 presents the total release of Species A and B as a function of time and container failure rate. For species $\mathrm{A}$, the instant failure model begins release 115 years after the problem start time and has the lowest total release. This is due to the releases starting later and the effects of radioactive decay. The total release is less than 0.07 grams from an initial inventory of 1.0 grams. The release for the Gaussian failure model begins at the earliest of the three models due to the tails of this distribution. The uniform failure model releases the most of species A, approximately 0.075 grams. All of species A that decays prior to release is converted to Species B. The release of Species B is displayed in Figure 1. In this case, the instant failure model has the highest total release of Species B, releasing 0.54 grams. The cumulative release at the end of the problem simulation time is within $1 \%$ for all three container failure models. Thus, in terms of total mass release, the result is insensitive to container failure rate. 
Figure 2 displays the concentration in the solution contacting the waste form as a function of time. As material is released from the waste form, the concentration increases. It decreases in time due to radioactive decay and advection moving the radionuclides away from the waste form. In both cases, Figure 2, the instantaneous failure model has the highest solution concentration. This is expected because in this model, all containers fail at a single time. For Species A, the peak concentration is $210^{-9} \mathrm{~g} / \mathrm{cm}^{3}$ when instantaneous failure occurs. For the Gaussian failure distribution and uniform failure rates, the peak concentration is less than $310^{-10}$ $\mathrm{g} / \mathrm{cm}^{3}$, almost an order of magnitude lower than the instantaneous case. For species B, similar results occur. For the instantaneous failure model, the peak concentration is $7.110^{-9} \mathrm{~g} / \mathrm{cm}^{3}$. For the Gaussian and uniform failure rates, the peak concentration is less than $1.310^{-9} \mathrm{~g} / \mathrm{cm}^{3}$. For the uniform failure rate, the peak in Species A concentration occurs approximately between 90 and 100 years. Radioactive decay causes the concentration to decrease after this time even though additional containers fail until 165 years. For species B and a uniform container failure rate, the concentration increases until 165 years when all containers have failed. After this time, the concentration decreases due to transport away from the waste form. For the Gaussian failure rates, the concentration follows a smoother distribution reflecting the container failure rate.

The difference in predicted concentration as a function of the failure model is a function of many parameters including radioactive decay, container failure rate, waste form release rate, and the parameters that define transport away from the waste form. However, as shown in this example, it may be substantial. Considering that most performance objectives for a waste disposal facility are concentration or dose (which is linearly proportional to concentration) based, the use of distributed failure models can have a significant impact when assessing performance.

At this point, the analyst can make technically defensible decisions about data needs and conceptual approach to modeling the release of radioactivity from the waste package. In the preceding example, it is clear that if the criteria for demonstrating safety is the cumulative amount released, there is little justification for using a distributed failure model and for collecting the data necessary to support such a model. However, if the criteria is the peak concentration, and an order of magnitude reduction is meaningful in terms of meeting regulatory limits, the analyst can make a case for using a distributed container failure model and collecting the data to support the failure distribution to be sued in the safety assessment. 


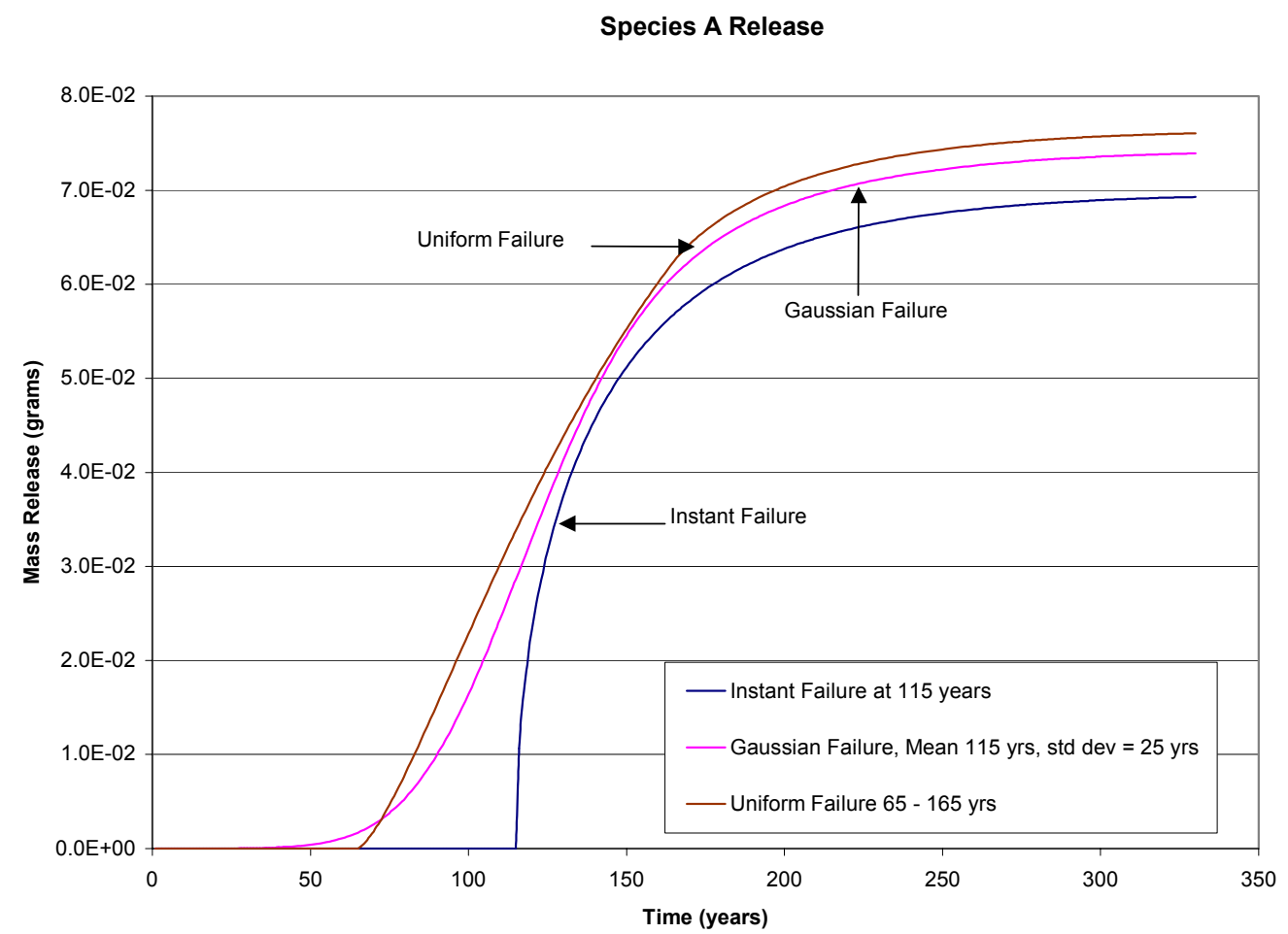

Species B Release

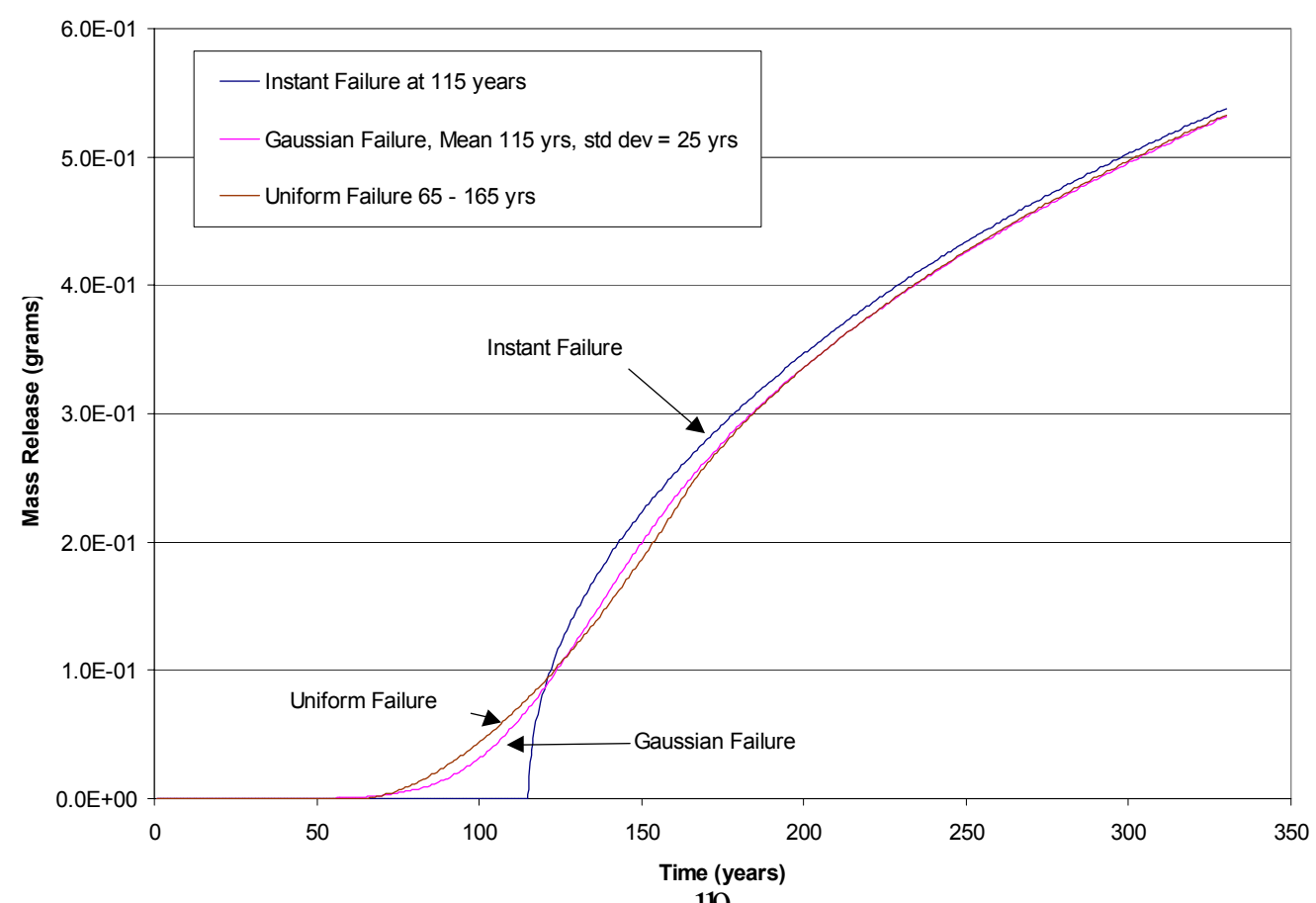

in

Figure 1 Cumulative Release of Species A and B for three failure rates. 
Species A Concentration

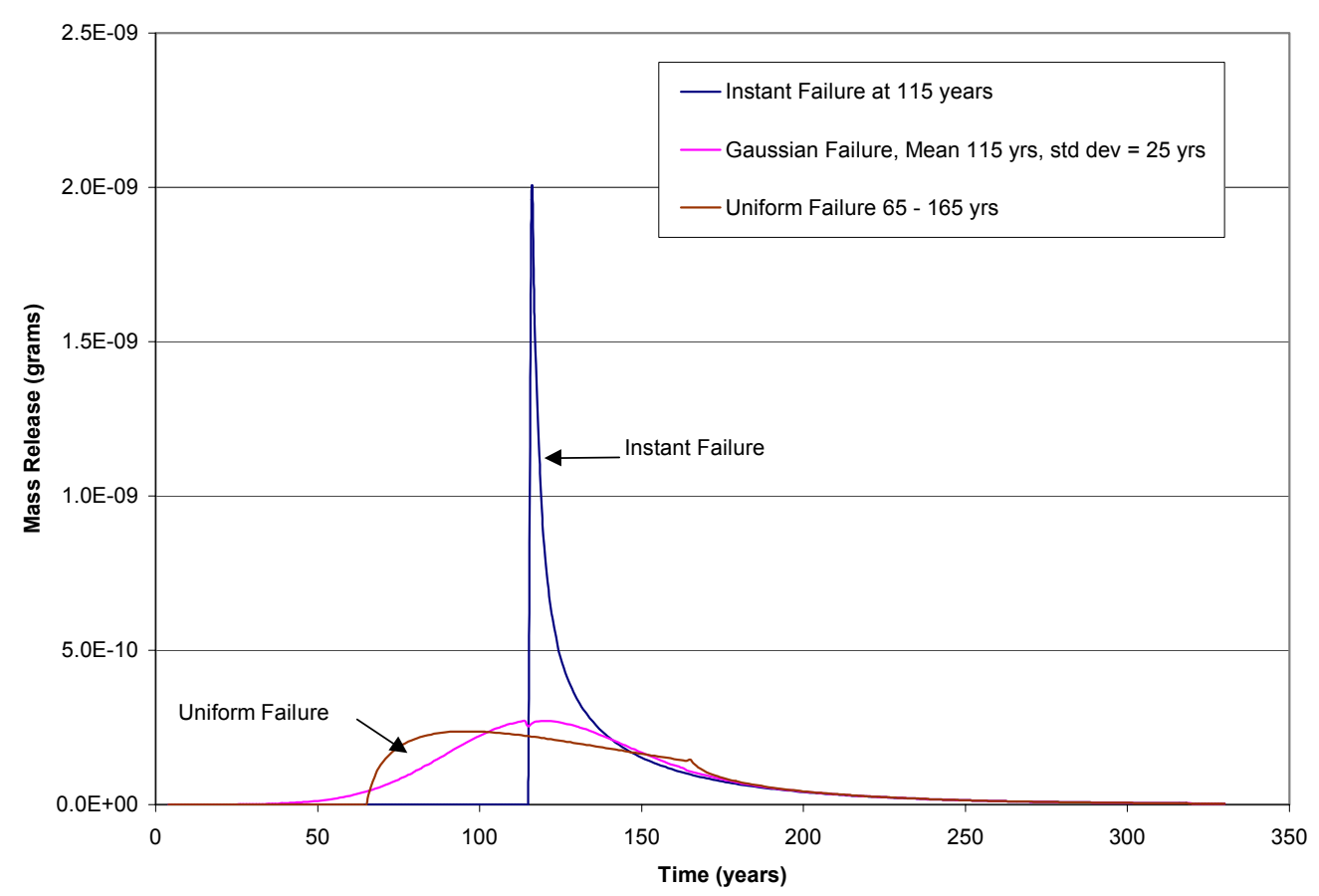

Species B Concentration

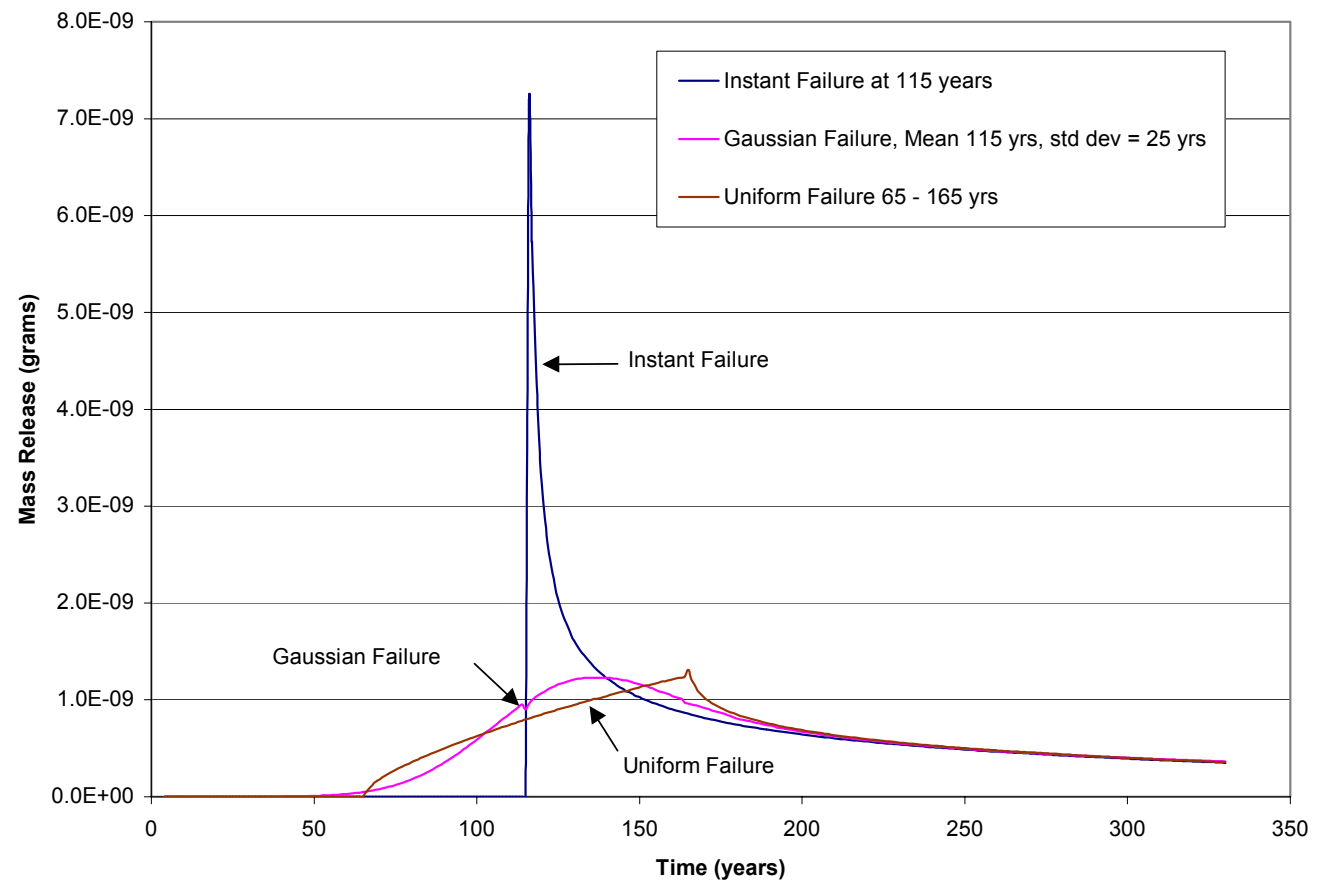

Figure 2 Concentration of Species A and B over time for three different container failure rates. 


\subsection{Example of the Role of Waste Form Performance on Safety Assessment}

It is clear that waste form performance can have a pronounced effect on release. In the most conservative calculations, the waste form is assumed to instantly release the entire inventory. This approach is often used whenever data are unavailable to support more detailed release calculations or in cases when this assumption does not change the demonstration that regulatory risk or dose based limits are not exceeded. Assuming instant release is the easiest to justify, (it can not be worse than that, although when ingrowth is an issue even this may not be true) and requires the least data (only the total inventory is required). However, in most cases, credit will have to be claimed for controlled release performance for the waste forms that contain the bulk of the activity.

For cement waste forms data often support use of a diffusion controlled release model. To examine the effects of waste form performance on release two examples will be provided. In the first, example the cumulative fractional release from a 200 liter drum is presented as a function of waste form diffusion coefficient, Figure 3. Three diffusion values were used, $10^{-10}, 10^{-12}$, and $10^{-14} \mathrm{~m}^{2} / \mathrm{s}$. The $10^{-10} \mathrm{~m}^{2} / \mathrm{s}$ value represent the maximum acceptable value for a waste form in the United States. Measured values for cement waste forms are generally between $10^{-12}$ and $10^{-16}$ $\mathrm{m}^{2} / \mathrm{s}$ depending on the radionuclide as well as the cement composition.

\section{Cumulative Fractional Release from a 200 liter waste form as a function of Diffusion Coefficient}

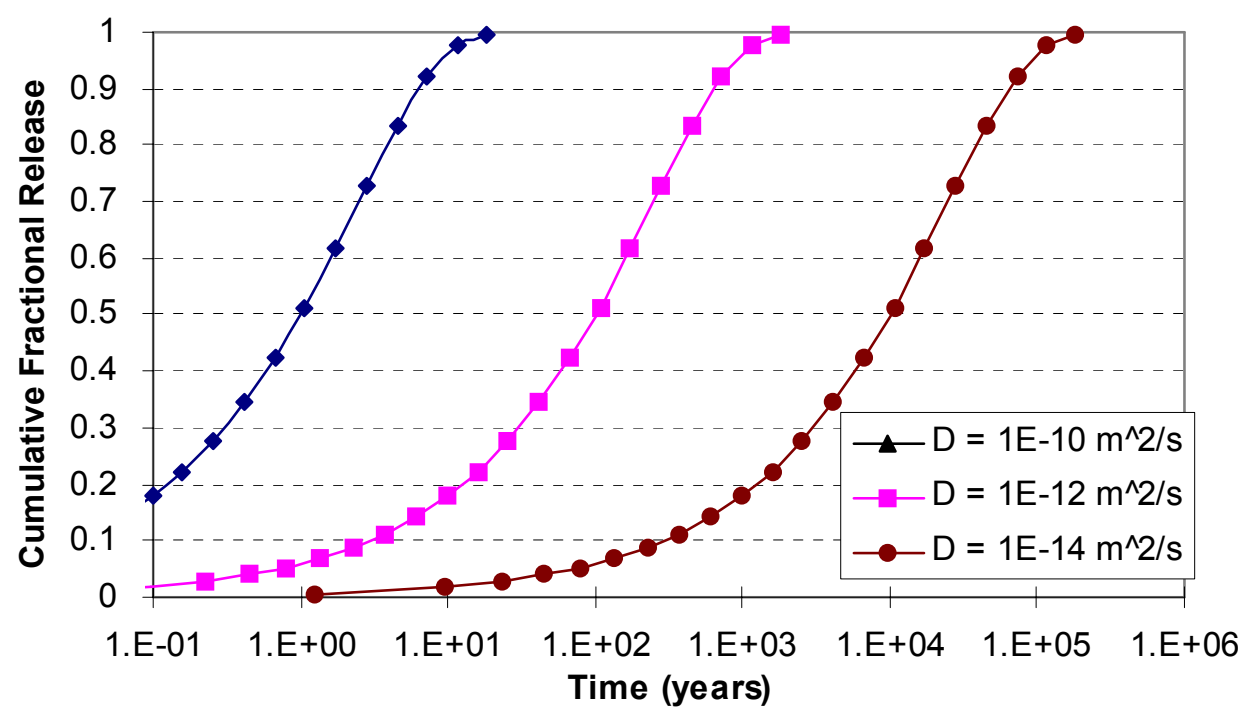

Figure 3 Cumulative fractional release from a 200 liter waste form 
From the semilog plot presented Figure 3 it is seen that the diffusion coefficient has a pronounced effect on release. Having a diffusion coefficient of $10^{-10} \mathrm{~m}^{2} / \mathrm{s}$ releases approximately $50 \%$ of the mass in the first year. Thus, it may be only a factor of two better than the instant release model in terms of peak concentration. The release rate for the diffusion controlled model decreases monotonically with time. Therefore, the first year has the highest release rate. For a diffusion coefficient of $10^{-12} \mathrm{~m}^{2} / \mathrm{s}$ the total released is just under $6 \%$, and for a diffusion coefficient of $10^{-14} \mathrm{~m}^{2} / \mathrm{s}$, less than $0.6 \%$ is released in the first year.

Often leaching experiments for cement waste forms have led to formation of a thin carbonate layer at the edge of the waste form. Once this layer is formed, the release rates are often substantially reduced. In the next example, a comparison is made between the release rate for a 200 liter waste form with a diffusion coefficient of $10^{-12} \mathrm{~m}^{2} / \mathrm{s}$ and a second waste form that has a thin, $0.001 \mathrm{~m}$, surface layer that acts as a diffusion barrier. Two different values of the reduced value of the diffusion coefficient were used in the example, $10^{-14} \mathrm{~m}^{2} / \mathrm{s}$ and $10^{-16} \mathrm{~m}^{2} / \mathrm{s}$ while in both cases the bulk of the waste form has a $10^{-12} \mathrm{~m}^{2} / \mathrm{s}$ diffusion coefficient.

Figure 4 presents the cumulative fractional release over 10 years for the three cases on a semilog plot. Formation of a thin film leads to a substantial reduction in the release rate. In this example, if the outer $1 \mathrm{~mm}$ of the waste form had a diffusion coefficient of $10^{-14} \mathrm{~m}^{2} / \mathrm{s},(2$ orders of magnitude less than the bulk diffusion coefficient) the release rate was decreased by an order of magnitude. For a surface film diffusion coefficient of $10^{-16} \mathrm{~m}^{2} / \mathrm{s}$, the release is three orders of magnitude less than without the diffusion barrier.

Effects of Thin Film Diffusion barrier on Release

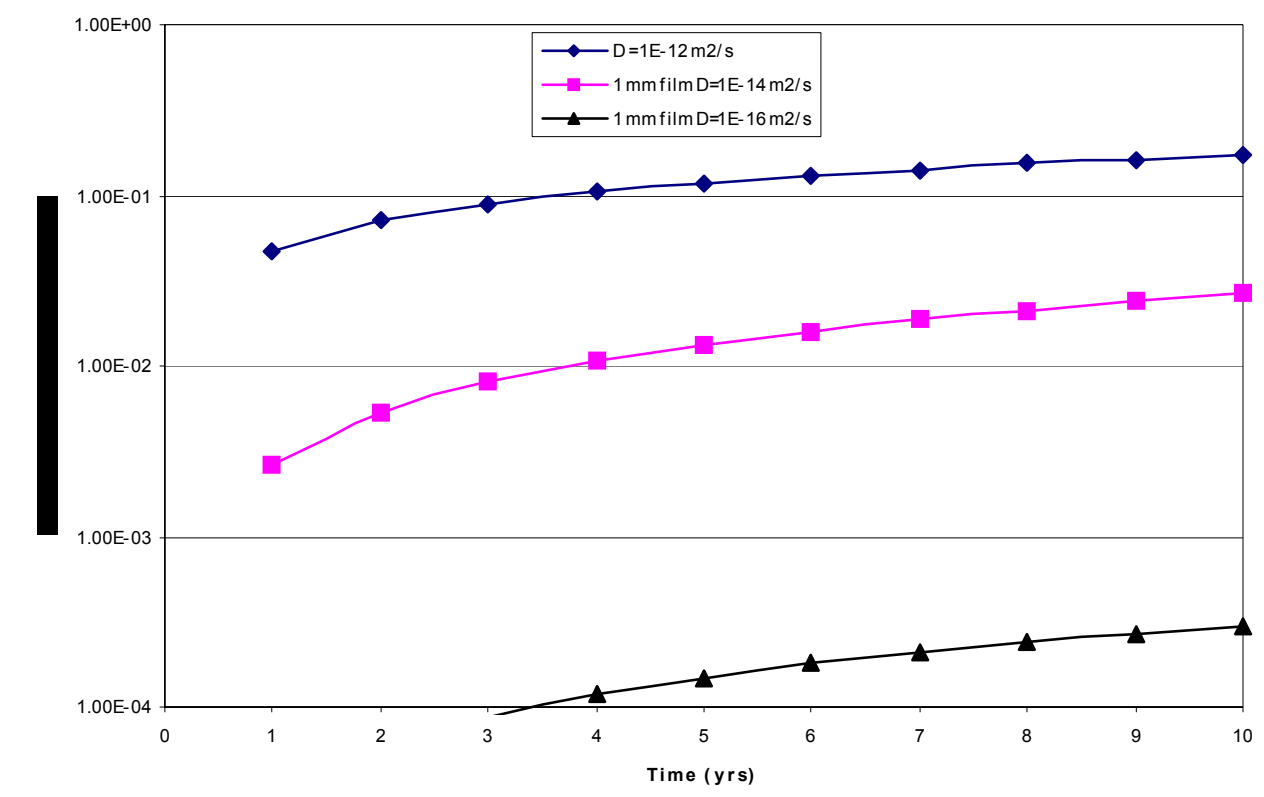

Figure 4 Effects of $1 \mathrm{~mm}$ Diffusion Barrier on Cumulative Fractional Release 
The analyst can use the type of information in these two examples to determine if it is necessary to collect data on diffusion coefficients from waste forms or on the formation of thin diffusion barrier on waste forms. As more information is required, the level of uncertainty increases and the amount of supporting information needed to defend the data increases. For example, at the most conservative level, assuming total release from the waste form, data on diffusion coefficients are not needed. If the analysis assumes diffusion is the rate controlling release mechanism, data must be collected on the waste form geometry and diffusion coefficients must be measured for the anticipated range of environmental and waste form compositions that may occur. This will lead to a collection of diffusion coefficient values and evidence will have to be supplied to support selecting values for the assessment. If the conceptual model selected for the safety assessment goes one step further and relies on the formation of a thin film on the surface of the waste form that acts as a diffusion barrier, the amount of data required to support this model increases again. In this case, questions pertaining to the time it takes to form the film (if it takes more than one year, it may be too slow to impact on peak dose), the geochemical conditions leading to film formation, and the thickness and stability of the film over time all need to be addressed. Thus the analyst must judge if the added time and expense to collect the data and the added risk in obtaining regulatory acceptance of the data and conceptual model justify the benefit the data will provide in terms of leading to lower predicted release rates and ultimately to lower dose or risk to man. If it can be shown that a simple conceptual model is defensible and helps to meet safety assessment dose limits, more complex models are not warranted .

\subsection{Conclusions}

Safety assessment for low and intermediate level wastes is a complicated process involving assumptions about the appropriate conceptual model to use and the data required to support these models. Typically due to the lack of long-term data and the uncertainties from lack of understanding and natural variability, the models used in safety assessment are simplistic. However, even though the models are simplistic, waste container and waste form performance are often central to the case for making a safety assessment. This paper provided an overview of the waste container and waste package performance models and data requirements. An example of the impacts of distributed container failure times on cumulative release and peak concentration was provided to illustrate some of the complexities in safety assessment and how modeling could be used to support the conceptual approach in safety assessment and define data requirements. The key point of the example is that modeling work can be used prior to extensive data collection to define the conceptual approach to safety assessment and data needs. Two examples of the role of the waste form in controlling release were presented to illustrate the importance of waste form performance to safety assessment. These examples highlight the difficulties in changing the conceptual model from something that is conservative and defensible (such as instant release of all the activity) to more representative conceptual models that account for known physical and chemical processes (such as diffusion) Adding model complexity adds to data requirements and adds to the risk that the data will not be acceptable to regulatory agencies. These added costs must be balanced against the benefits obtained for the entire safety assessment. In general, modeling of 
waste package performance is a critical step in supporting a safety assessment and should be used to support the selection of conceptual models and define data requirements.

\subsection{References}

ANS (1986). Measurement of the Leachability of Solidified Low-Level Radioactive Wastes, American Nuclear Society, Standards Committee Working Group ANS 16.1.

COWGILL, M.G. (1992). Lifetime Estimates for Polyethylene High Integrity Containers,@ Technical Letter Report, WM-3276-16 (Brookhaven National Laboratory, Upton, NY).

COWGILL, M.G. and SUlLIVAN, T.M. (1993). "Source Term Evaluation for Radioactive Low-level Waste Disposal Performance Assessment," NUREG/CR-5911, BNL-NUREG-52334 (U.S. Nuclear Regulatory Commission, Washington, D.C.).

DEHMEL, J-C., LOOMIS, D. MAURO, J., and KAPLAN, M. (1994). "Characterization of Class A Low-Level Radioactive Waste 1986 - 1990, Main Report - Part A" NUREG/CR-6147, 2. (U.S. Nuclear Regulatory Commission, Washington, D.C.).

DOLINAR, G.M., RATTAN, D.S., and ROWAT, J.H. (1994). "AECL, IRUS Near Surface Low-Level Waste Repository," Presented at the 16th Annual U.S. Department of Energy LowLevel Radioactive Waste Management Conference, (U.S. Department of Energy, Washington, D.C.)

GERHOLD, W.F., ESCALANTE, E. and SANDERSON, B.T. (1981). "The Corrosion Behavior of Selected Stainless Steels in Soil Environments," NBSIR 81-2228 (National Bureau of Standards, Washington, D.C.).

HAUSER, W. and KOESTER, R. (1989). "Evaluation of Long-Term Durability of Low and Intermediate-Level Waste Packages," pages 795-799 in Waste Management '89 2, . 
KOZAK, M.W., CHU, M.S.Y., and MATTINGLY, P.A. (1990). "A Performance Assessment Methodology for Low-Level Waste Facilities," NUREG/CR-5532, SAND900375 (U.S. Nuclear Regulatory Commission, Washington, D.C.).

KOZAK, M.W., OLAGUE, N.E., RAO, R.R., and McCORD, J.T. (1993). "Evaluation of a Performance Assessment Methodology for Low-Level Radioactive Waste Disposal Facilities," NUREG/CR-5927, SAND91-2802, 1 (U.S. Nuclear Regulatory Commission, Washington, D.C.).

MACKINNON, R.J. and SULLIVAN, T.M. (1994). "Multispecies Models for Assessing the Release of Radionuclides from Low-Level Waste Shallow Land Disposal Units," Waste Management '94. R.G. Post, ed.

MARQUE, Y. (1994). "Centre de l'aube Design and Safety Assessment Approach," 16th Annual U.S. Department of Energy Low-Level Radioactive Waste Management Conference,(U.S. Department of Energy).

NCRP (1996). National Council on Radiation Protection and Measurements. Screening Models for Releases of Radionuclides to Atmosphere, Surface Water, and Ground, NCRP Report No. 123 I, (National Council on Radiation Protection and Measurements, Bethesda, Maryland)

NRC (1991). "Technical Branch Position on Waste Form, Revision 1," Office of Nuclear Materials Safety and Safeguards, (U.S. Nuclear Regulatory Commission., Washington, D.C.).

PESCATORE, C., (1991). "Improved Expressions for Modeling Diffusive, Fractional Cumulative Leaching form Finite-Size Waste Forms," Waste Management 10.155-159.

ROLES, G.W., (1990). "Characteristic of Low-level Radioactive Waste Disposed During 1987 through 1989," NUREG-1418, (U.S. Nuclear Regulatory Commission, Washington, D.C.)

ROMANOFF, M., (1957). "Underground Corrosion," National Bureau of Standards Circular, 579.

SELANDAR, W.N., WILKINSON, S.R. and ROWAT J.H. (1991). "A Vault Mass Transfer Model for LLRW," TR-509 Atomic Energy of Canada Limited, Chalk River, Canada.

SERNE, R.J., ARTHUR, R.C. and. KRUPKA, K. M. (1990). "Review of Geochemical Processes and Codes for Assessment of Radionuclide Migration Potential at Commercial LLW Sites," (NUREG/CR-5548, PNL-7285, (U.S. Nuclear Regulatory Commission, Washington, D.C.). 
SULLIVAN, T.M., and SUEN, C.J., (1989). "Low-level Waste Shallow Land Disposal Source Term Model: Data Input Guides," NUREG/CR-5387, BNL-NUREG-52206, (U.S. Nuclear Regulatory Commission, Washington, D.C.).

SULLIVAN, T.M. and. SUEN, C.J. (1991). "Low-level Waste Source Term Model Development and Testing," NUREG/CR-5681, BNL-NUREG-52280, (U.S. Nuclear Regulatory Commission, Washington, D.C.).

SULLIVAN, T.M. and COWGILL, M.G. (1991). Evaluation of the Data Available for Estimating Release Rates from Commercial Low-Level Waste Packages,"13th Annual DOE Low-Level Waste Management Participants Meeting, also as BNL-NUREG-46766 (U.S. Department of Energy, Washington, D.C.).

SULLIVAN, T.M., (1993) "DUST - Disposal Unit Source Term: Data Input Guide." NUREG/CR-6041, BNL-NUREG-52375, 1993.

SULLIVAN, T.M., R. J, MACKINNON, R.R. KINSEY, A. ARONSON, and M.

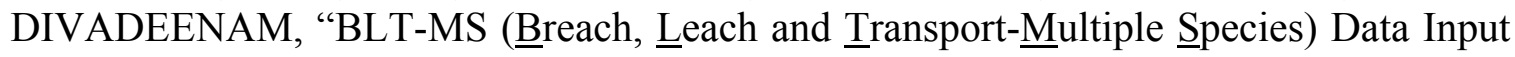
Guide: A Computer Model for Simulating Release of Contaminants from a Subsurface Low-Level Waste Disposal Facility", NUREG/CR-6492, BNL-NUREG-52509, 1996.

SULLIVALN, T.M, (2000) "DUST-MS - Disposal Unit Source Term Multiple Species Data Input Guide", BNL - Informal Report, 2000.

SULLIVAN, T.M., and F. LEMOS, (2001), 'Distributed Container Failure Models for the DUST-MS Computer Code,” Waste Management '2001.

YIM, M.S., (1994). "Gas-Phase Release of Radionuclides from Low-Level Radioactive Waste Disposal Facilities," Ph.D. Dissertation, (Harvard University, Boston, MA). 